\title{
PENGARUH RELIGIUSITAS, ADVERSITY QUOTIENT DAN LINGKUNGAN KERJA NON FISIK TERHADAP STRES KERJA
}

\author{
I Kadek Andika Budi Utama ${ }^{1}$ \\ Ida Bagus Ketut Surya ${ }^{2}$ \\ ${ }^{1,2}$ Fakultas Ekonomi dan Bisnis Universitas Udayana (Unud), Bali, Indonesia \\ E-mail: andikautamaa@gmail.com
}

\begin{abstract}
ABSTRAK
Penelitian ini bertujuan untuk mengetahui seberapa besar perubahan pada variabel Stres Kerja di pengaruhi oleh variabel religiusitas, adversity qoutent dan lingkungan kerja non fisik. Penelitian dilakukan di Bank Perkreditan Rakyat Sri Partha Bali sebanyak 55 responden. Jumlah responden ditentukan menggunakan metode penentuan sampel probability sampling. Data diperoleh dengan menyebarkan kuesioner yang dianalisis menggunakan teknik analisisregresi berganda, Uji t , uji validitas. Hasil pengujian dalam penelitian ini adalah religiusitas berpengaruh negatif terhadap stres kerja. Adversity qoutient berpengaruh negatif terhadap stres kerja. Lingkungan kerja non fisik berpengaruh negatif terhadap stres kerja.
\end{abstract}

Kata kunci: stres kerja, adversity qoutent, religiusitas, lingkungan kerja non fisik

\section{ABSTRACT}

This study aims to determine how much change in the Job Stress variable is influenced by variables of religiosity, adversity qoutent and non-physical work environment. The study was conducted at the Bali Sri Partha Rural Bank of 55 respondents. The number of respondents was determined using the method of determining probability sampling. Data obtained by distributing questionnaires were analyzed using multiple regression analysis techniques, $t$ test, validity test. The test results in this study are religiosity has a negative effect on work stress. Adversity qoutient has a negative effect on work stress. Non-physical work environment has a negative effect on work stress.

Keywords: work stress, adversity qoutent, religiosity, non physical work environment 


\section{PENDAHULUAN}

Kehidupan modern dewasa ini telah menuntut manusia hidup bersaing untuk memenuhi kebutuhan baik fisik, mental, emosional, material, maupun spiritual. Seringkali pada usaha pemenuhan kebutuhan-kebutuhan tersebut mendapatkan banyak rintangan dan hambatan yang mengakibatkan manusia mengalami tekanan jiwa berupa stres. Stres merupakan hal yang melekat pada kehidupan manusia. Siapa saja dalam bentuk tertentu dalam kadar berat atau ringan dan dalam jangka panjang atau pendek, pernah atau akan mengalaminya. Menurut Siagian (2016:43) stres merupakan kondisi ketegangan yang berpengaruh terhadap emosi, jalan pikiran, dan kondisi fisik seseorang.

Stres yang tidak dapat diatasi dengan baik biasanya berakibat pada ketidak mampuan seseorang berinteraksi dengan lingkungannya, baik lingkungan pekerjaan maupun di luar pekerjaaan. Manusia akan cenderung mengalami stres apabila ia kurang mampu menyesuaikan antara keinginan dengan kenyataan yang ada, baik kenyataan yang ada di dalam maupun di luar dirinya. Stres kerja yang dialami oleh karyawan tentunya akan merugikan organisasi yang bersangkutan karena kinerja yang dihasilkan menurun, tingkat absensi tinggi serta turn over yang tinggi yang pada akhirnya menyebabkan biaya yang bertambah besar.

Stres yang berkepanjangan dikaitkan dengan kecemasan kronis, penyakit psikosomatik dan berbagai masalah emosional lainnya (Caughey, 2016). Stressor adalah suatu tuntutan, situasi atau keadaan yang menghilangkan ekuilibrium seseorang dan memicu respons stres dari peningkatan dorongan otonom. Stres yang berkepanjangan dikaitkan dengan kecemasan kronis, penyakit psikosomatik 
dan berbagai masalah emosional lainnya (Taylorbrown et al., 2016). Burnout dapat lebih spesifik dikonseptualisasikan sebagai tiga dimensi yang saling terkait: kelelahan emosional, depersonalisasi, dan pengurangan pencapaian pribadi. Kelelahan emosional adalah penurunan sumber daya psikologis (Hallberg dan Sverke, 2014).

Berdasarkan 15 tahun terakhir, hubungan antara religiusitas terhadap stres telah diperiksa secara ekstensif. Studi menunjukkan bahwa keyakinan agama, praktik dan afiliasi membantu mengurangi gejala fisik stres khususnya dalam stres kerja (Koenig et al., 2001; Levin et al., 2012). Keyakinan religius ini mempengaruhi bagaimana individu membentuk ide-idenya tentang kehidupannya, dan bagaimana individu menginterpretasikan dunianya (Carone and Barone, 2001). Religiusitas mempunyai peran penting dalam mengelola stres dalam bekerja, Religiusitas dalam diri seseorang dapat memberikan individu pengarahan atau bimbingan, dukungan, dan harapan, seperti halnya pada dukungan emosi (Kasberger, 2015). Melalui berdoa, ritual dan keyakinan agama dapat membantu seseorang dalam saat mengalami stres kehidupan, dan stres saat bekerja karena adanya pengharapan dan kenyamanan (Rammohan dan Subbakrishna, 2013).

Sumber daya manusia yang dimiliki perusahaan adalah mahluk sosial dan juga mahluk beragama. Menurut Patchsawang dan Duchon (2012) religiusitas dapat bertransformasi dimulai dari tempat kerja, ketika organisasi atau perusahaan membuka diri untuk meningkatkan spiritualitas karyawan mereka sendiri, sehingga dapat menangani karyawan sebagai manusia utuh dalam hal fisik, mental, kebutuhan emosional, dan spiritual. Menurut Cornwall et al. (2014) 
religiusitas didefinisikan dalam hal kecerdasan pada pengetahuan dan keyakinan agama, di samping pengaruhnya yang dikaitkan dengan keterikatan emosional atau perasaan tentang agama. Selanjutnya, perilaku yang diungkapkan, seperti afiliasi dan kehadiran gereja, pembacaan alkitab, dan berdoa tingkat di mana seorang individu dianggap sebagai orang yang religius selain dari keyakinan agama yang berbeda dan cara keyakinan tersebut dimanifestasikan diklasifikasikan sebagai religiusitas (Vitell dan Singhapakdi, 2016).

Menurut Paul G. Stoltz (2015) mengintegrasikan hasil lebih dari 500 investigasi yang dilakukan oleh lusinan ulama sebagai dasar teori, dan mengusulkan adversity quotient (AQ) berdasarkan konsep tiga ilmu, psikologi kognitif, dan neuroimmunology mental dan neurofisiologis. Apa yang disebut Adversity Quotient adalah untuk mengukur standar tanggapan orang terhadap kesulitan, dan untuk memprediksi orang mana yang dapat mengatasi kesulitan dan yang tidak dapat bertahan dari ujian. Adversity quotient juga dapat digunakan untuk memahami apakah orang dapat memenuhi potensi dan mencapai tujuan. Adversity quotient juga dapat digunakan untuk memprediksi orang mana yang akan menyerah setengah dan yang akan bertahan sampai akhir untuk tujuan mereka (Stoltz, 2015).

Daya juang atau adversity quotient (AQ) adalah kemampuan seorang individu dalam mengatasi kesulitan dan hambatan dalam hidupnya (Phoolka dan Kaur, 2012). Terdapat 4 dimensi yang membentuk daya juang, yaitu Control, Origin, Ownership, Reach, dan Endurance yang biasa disingkat dengan CO2RE. Menurut Stolz (1997) dapat meramalkan siapa yang mampu mengatasi kesulitan 
dan siapa yang akan hancur. Adversity quotient juga mampu meramalkan siapa yang menyerah dan siapa yang bertahan. Selain itu Adversity quotient juga dapat meramalkan siapa yang melampaui harapan-harapan atas kinerja dan potensi mereka serta siapa yang akan gagal.

Lingkungan kerja berkaitan dengan segala sesuatu yang berada di tempat kerja. Lingkungan kerja adalah segala kondisi yang berada di sekitar karyawan yang dihubungkan dengan terjadinya perubahan psikologis dalam diri karyawan yang bersangkutan (Schultz 2013). Selain itu definisi lain dikemukakan oleh Sedarmayanti (2009:26) yang mendefinisikan lingkungan kerja sebagai keseluruhan alat perkakas dan bahan yang dihadapi, lingkungan sekitarnya dimana seseorang bekerja, metode kerjanya, serta pengaturan kerjanya baik sebagai perseorangan maupun sebagai kelompok. Menurut Sedarmayanti (2009:26) "Lingkungan kerja non fisik adalah semua keadaan yang terjadi yang berkaitan dengan hubungan kerja, baik hubungan dengan atasan maupun hubungan sesama rekan kerja, ataupun hubungan dengan bawahan". Pendapat lain muncul mengenai lingkungan kerja non fisik dan serupa dengan pendapat Sedarmayanti di atas yaitu diungkapkan oleh Nitisemito (2000:171), perusahaan hendaknya mencerminkan kondisi yang mendukung kerjasama antara tingkat atasan, bawahan maupun yang memiliki jabatan yang sama di perusahaan.

Bank Perkreditan Rakyat Sri Partha Bali tentu tidak terlepas dari berbagai masalah, berdasarkan hasil wawancara menunjukkan bahwa masih banyak karyawan yang menyatakan bahwa diri mereka mengalami stres, situasi stres seperti ini di rasakan oleh karyawan Bank Perkreditan Rakyat Sri Partha Bali. 
Sebagai salah satu yang dikemukakan oleh karyawan Bank Perkreditan Rakyat Sri Partha Bali adalah ketidak mampuan seorang karyawan untuk menyelesaikan tugas dengan tepat pada waktunya, ini merupakan salah satu indikator dalam stres kerja yaitu beban kerja yang berlebih.

Permasalahan lain yang terdapat di Bank Perkreditan Rakyat Sri Partha Bali adalah kurangnya kemampuan karyawan yang memiliki adversity qoutient yang baik, sehingga karyawan mudah menyerah dalam menghadapi masalah sehingga mudah mendapatkan tekanan atau desakan waktu sehingga menyebabkan stres kerja terhadap karyawan (Leiter dan Maslach, 2016). Selain permasalahan di atas hasil wawancara juga menunjukan permasalahan lain, yaitu permasalahan yang terjadi antar karyawan Bank Perkreditan Rakyat Sri Partha Bali menyebabkan tekanan dalam individu karyawan sehingga karyawan sangat terbebani oleh beban hubungan yang tidak harmonis antar karyawan.

Stres dapat didefinisikan sebagai keadaan hipotetis yang disebabkan oleh kekuatan lingkungan misalnya stres dan dimanifestasikan oleh reaksi pada berbagai tingkat fisiologis, psikologis, dan sosial (Tolman dan Rose, 2014). Beberapa efek fisiologis umum dari paparan terhadap stres adalah hipertensi, penyakit pada pola makan, tidur, penyakit paru-paru, dan penyalah gunaan substitusi (Harrell, 2016). Konsekuensi psikologis dapat mencakup depresi, kegelisahan, ketidakberdayaan, frustrasi, ketakutan, dan keputusasaan (Thompson, 2002). Mereka dengan tingkat stres yang meningkat juga dapat menderita efek seperti menurunkan harga diri dan kepuasan hidup (Utsey et al., 2002). Menurut Mangkunegara (2017), stres merupakan perasaan tertekan yang 
dialami karyawan saat menghadapi pekerjaan. Hal ini dapat terlihat dari emosi yang tidak stabil, perasaan tidak tenang, tekanan darah meningkat serta mengalami gangguan pencernaan. Sedangkan definisi stress menurut Robbins (2007:120) adalah suatu keadaan yang dialami oleh individu dalam menghadapi sebuah peluang, kendala, atau tuntutan yang hasilnya dianggap tidak pasti namun penting.

Berdasarkan pengertian di atas dapat dikemukakan stres merupakan respon atau tindakan yang dilakukan seseorang dalam menanggapi perubahan yang ada di sekitarnya. Stres dapat didefinisikan sebagai " keadaan hipotetis yang disebabkan oleh kekuatan lingkungan (misalnya stres) dan dimanifestasikan oleh reaksi pada berbagai tingkat fisiologis, psikologis, dan sosial (Tolman dan Rose, 2014). Konsekuensi psikologis dapat mencakup depresi, kegelisahan, ketidak berdayaan, frustrasi, ketakutan, dan keputusasaan (Thompson, 2002). Mereka dengan tingkat stres yang meningkat juga dapat menderita efek seperti menurunkan harga diri dan kepuasan hidup (Utsey et al., 2002).

Menurut Allport dan Ross (2015) dalam teori religiusitas individu yang berorientasi intrinsik memandang agama sebagai tidak mementingkan diri sendiri, sebagai nilai tertinggi yang harus dicapai untuk tujuannya sendiri. Menurut teori religius ini, individu yang secara intrinsik berorientasi untuk menjadi religius adalah karena mereka percaya dunia dan umat manusia adalah benar-benar baik dan bahwa yang tertinggi berada di pusat keduanya. Mereka merasa keyakinan dan praktik keagamaan berakhir pada diri mereka sendiri, karena mereka 
memberikan kedamaian dan kesejahteraan dan membuat dunia menjadi tempat yang lebih baik.

Orang yang berorientasi ekstrinsik lebih cenderung menggunakan agama sebagai sarana untuk tujuan yang diinginkan - yaitu, agama untuk tujuan utilitarian. Afiliasi agama, perilaku dan keyakinan, bagi individu-individu ini, adalah cara untuk mendapatkan hal-hal lain atau mencapai tujuan lain. Ross (2014) mencatat bahwa teori religius individu jatuh pada suatu kontinum antara eksternalitas lengkap dan internalisasi lengkap. Secara umum, teorinya adalah bahwa individu-individu religius, terutama yang paling termotivasi secara intrinsik , memiliki manfaat ketika mengelola stres (Park et al., 2013 ; Pollard dan Bates, 2014).

Religiusitas menurut Kamus Besar Bahasa Indonesia (KBBI) berarti taat pada agama, sehingga dapat dikatakan, bahwa religiusitas adalah ketaatan sebagai ketaatan seorang individu terhadap perintah agama yang diyakininya, pengertian lain dari religiusitas dalam beberapa pendapat sebagaimana berikut: dalam Kamus besar bahasa Indonesia mendefinisikan beberapa istilah yang saling berhubungan, yaitu: 1) Religi ( religion, kata benda ) agama, kepercayaan, penyembahan, penghambaan, terhadap satu kekuatan supernatural yang dianggap sebagai Tuhan yang menentukan nasib manusia, suatu ungkapan terlembaga atau formal dari kepercayaan tersebut. Religius (kata sifat) bersifat agamis, berhubungan dengan agama, sesuai dengan prinsip-prinsip suatu agama. Keberagamaan (religiousness, kata benda) keadaan atau kualitas seseorang menjadi religious. Religiusitas 
(religiosity, kata benda) ketaatan pada agama atau keberagamaan (Departemen Pendidikan Nasional, 2011: 265).

Menurut Sudarsono (2008:86) Secara esensial agama merupakan peraturanperaturan dari Tuhan Yang Maha Esa berdimensi vertikal dan horizontal yang mampu memberi dorongan terhadap jiwa manusia yang berakal agar berpedoman menurut peraturan Tuhan dengan kehendaknya sendiri, tanpa dipengaruhi untuk mencapai kebahagiaan hidup di dunia dan kebahagiaan di akhirat kelak. Religiusitas dan agama memang merupakan satu kesatuan yang tidak dapat dipisahkan (Andisti dan Ritandiyono 2008). Bila dilihat dari kenampakannya, agama lebih menunjukkan kepada suatu kelembagaan yang mengatur tata penyembahan manusia kepada Tuhan, sedangkan religiusitas lebih menunjuk pada aspek yang ada di lubuk hati manusia. Religiusitas lebih menunjuk kepada aspek kualitas dari manusia yang beragama. Agama dan religiusitas saling mendukung dan saling melengkapi karena keduanya merupakan konsekuensi logis dari kehidupan manusia yang mempunyai dua kutub, yaitu kutub kehidupan pribadi dan kutub kebersamaannya di tengah masyarakat (Andisti dan Ritandiyono 2008).

Menurut Ancok dan Suroso (2009) mengemukakan bahwa keberagamaan atau religiusitas diwujudkan dalam berbagai sisi kehidupan manusia. Aktivitas beragama bukan hanya terjadi ketika seseorang melakukan perilaku ritual (beribadah) tapi juga ketika melakukan aktivitas lain yang didorong oleh kekuatan supranatural, bukan hanya aktivitas yang tampak dan dapat dilihat tetapi juga aktivitas yang tak tampak dan terjadi pada hati seseorang. Karena itu keberagamaan seseorang akan meliputi berbagai macam sisi dan dimensi. Dengan 
demikian dapat dikatakan bahwa agama adalah sistem yang berdimensi banyak. Berdasarkan definisi-definisi yang telah diperoleh, maka dapat dikemukakan bahwa religiusitas adalah suatu gambaran keadaan dalam diri seseorang yang mendorongnya bertingkah laku (baik tingkah laku yang tampak maupun tak tampak), bersikap, dan bertindak sesuai dengan ajaran-ajaran agama yang dianutnya.

Teori yang dikemukakan oleh Paul G. Stoltz mengintegrasikan hasil lebih dari 500 investigasi yang dilakukan oleh lusinan ilmuan sebagai dasar teori, dan mengusulkan Adversity Quotient (AQ) berdasarkan konsep tiga ilmu, psikologi kognitif, dan neuroimmunology mental dan neurofisiologis. Apa yang disebut Adversity Quotient adalah untuk mengukur standar tanggapan orang terhadap kesulitan, dan untuk memprediksi orang mana yang dapat mengatasi kesulitan dan yang tidak dapat bertahan dari ujian. Adversity Quotient juga dapat digunakan untuk memahami apakah orang dapat memenuhi potensi dan mencapai tujuan. Adversity Quotient juga dapat digunakan untuk memprediksi orang mana yang akan menyerah setengah dan yang akan bertahan sampai akhir untuk tujuan mereka (Stoltz, 2015).

Studi psikologi kognitif menunjukkan bahwa, mereka yang mengaitkan kemunduran dengan diri mereka sendiri cenderung disiksa oleh kesulitan, sementara mereka yang menghubungkannya dengan penyebab eksternal dan menyarankan bahwa upaya yang dilakukan dapat mengubah segalanya dapat terus bergerak maju. Tanggapan terhadap kesulitan mempengaruhi kinerja dan keberhasilan efisiensi individu (Seligman, 2013; Rotter, 2015). Studi 
neuropsikologi menemukan bahwa, struktur otak dapat membentuk kebiasaan, yang dapat segera terganggu dan diubah. Setelah kebiasaan orang dengan sengaja diubah, mereka akan membuang kebiasaan lama mereka dan menerima kebiasaan baru (Marc, 2015). Studi mental dan neuroimunologi menunjukkan bahwa, ada hubungan langsung antara respons terhadap frustrasi dan kesehatan fisik dan psikologis. Adversity Quotient akan mempengaruhi fungsi kekebalan tubuh, pemulihan pasca operasi, dan kemungkinan menderita penyakit kritis (Bartifai dan Schultzberg, 1993).

Adversity memiliki akar kata "adverse" yang berarti negatif atau bertolak belakang. Berdasarkan akar kata tersebut adversity memiliki arti yang luas. Mulai dari berita buruk, kesusahan, nasib sial sampai pada penyakit yang tak tersembukan, masa-masa sulit, kepedihan dan bencana. Adversity dapat juga dipahami sebagai sebuah keadaan tidak beruntung atau bencana, kesusahan dan digambarkan sebagai kecelakaan yang tak terelakan (Laksmono, 2017). Sementara Quotient selain berarti hasil akhir dari pembagian soal, juga dapat diartikan sejenis test seperti Test Kecerdasan (Intelligent Quotient) yang mana dalam hal ini quotient memberikan gambaran derajat atau tingkat kecerdasan individu dalam bentuk skor. Jadi berdasarkan akar katanya, Adversity Quotient berarti skor seseorang saat bertahan dalam kepedihan, kesulitan, bencana, kecelakaan atau situasi negatif lain.

Stoltz (2015) menyatakan Adversity Quotient adalah daya juang yang diuraikan sebagai derajat kemampuan seseorang dalam bertahan, menanggulangi situasi yang dianggapnya sebagai masalah, dan melampaui masalah yang 
dihadapi. Nashori (2007: 47) berpendapat bahwa adversity quotient merupakan kemampuan seseorang dalam menggunakan kecerdasannya untuk mengarahkan, mengubah cara berfikir dan tindakannya ketika menghadapi hambatan dan kesulitan yang bisa menyengsarakan dirinya. Leman (2007: 115) mendefinisikan adversity quotient secara ringkas, yaitu sebagai kemampuan seseorang untuk menghadapi masalah. Beberapa definisi di atas yang cukup beragam, terdapat fokus atau titik tekan, yaitu kemampuan yang dimiliki seseorang, baik fisik ataupun psikis dalam menghadapi problematika atau permasalahan yang sedang dialami.

Dengan hampir 95\% orang Amerika menyatakan bahwa mereka percaya ada Tuhan, dan $81 \%$ orang dewasa Amerika menunjukkan afiliasi agama tertentu (Kosmin et al., 2001), agama bukanlah sesuatu yang dapat diharapkan secara realistis oleh karyawan untuk "meninggalkan di depan pintu" " ketika mereka datang untuk bekerja (Conlin, 2009). Sementara penelitian tidak menunjukkan bahwa persentase orang Amerika yang lebih besar menjadi survei religius (Kosmin et al., 2001), menunjukkan kecenderungan yang meningkat bagi banyak umat beragama untuk menginginkan agar agama mereka diintegrasikan ke dalam semua bidang kehidupan mereka (Gibson, 2005). Hal ini setidaknya dapat dijelaskan oleh banyak konsekuensi positif yang ditemukan untuk mendampingi keyakinan dan praktik agama.

Penelitian ini dilakukan oleh Eugene J. Kutcher dari Rider University dan Jennifer Bragger dari Montclair State University, dengan judul "The Role of Religiosity in Stress, Job Attitudes, and Organizational Citizenship Behavior" 
yang di muat dalam Article inJournal of Business Ethics August 2010, ada sejumlah penjelasan yang mungkin untuk temuan ini. Satu penjelasan yang jelas adalah bahwa religiusitas memiliki dampak langsung pada tingkat stres yang dialami karyawan dan tingkat kelelahan yang dialami karyawan. Artinya, ketangguhan yang diberikan oleh keyakinan dan ketaatan beragama benar-benar mengurangi tingkat stres terkait pekerjaan yang dialami karyawan, sehingga kelelahan menjadi sesuatu yang bisa diperdebatkan.

Selanjutnya yaitu penelitian di lakukan oleh Mira Isminari (2011) dengan judul skripsi "Pengaruh Regiulitas dan Advesity Quotient Terhadap Stres Kerja Pada Agen Asuransi Jiwa Bersama Bumi Putra 1912" menemukan hasil penelitian yang dimana menunjukkan variabel religiusitas ada pengaruh yang negatif signifikan terhadap stres kerja. Jadi tinggi atau rendahnya religiusitas yang dimiliki oleh Agen asuransi Bersama Bumi Putra 1912 mempengaruhi stres kerja. Jika dilihat dari hasil temuan penelitian yang dilakukan oleh Mira Isminari (2011) melihat presentasi religiusitas yang tergolong tinggi sebesar 89 persen. Apabila dilihat secara perhitungan hasil penelitian ini sesuai dengan hasil penelitian Nove Ira (2003) mengenai hubungan antara tingkat religiusitas dengan stres kerja pada pekerja industri yang menyatakan bahwa religiusitas memiliki hubungan yang signifikan dengan stres kerja pada pekerja industri dengan koefisien korelasi 0,220 dengan taraf signifikansi sebesar 0.0. Hasil penelitian lain yang dilakukan Kresna Astri (2009) menyatakan bahwa adanya korelasi negatif secara signifikan antara stres kerjas dengan religiusitas pada partisipan, artinya semakin tinggi religiusitas seseorang maka semakin rendah stres kerjanya. 
$\mathrm{H}_{1}$ : Ada pengaruh negatif yang signifikan antara religiusitas terhadap stres kerja. Hubungan adversity qoutient dengan stres, stres adalah perasaan untuk ditekan, dan pengalaman subjektif individu terhadap variabel lingkungan (Adriaenssens et al., 2016). Selain itu, stres berarti keadaan psikologis individu ketika mereka tidak dapat beradaptasi atau merespon dengan benar hal-hal dalam situasi kehidupan (Tian, 2007). Oleh karena itu, stres kerja merupakan ancaman bagi pekerja yang disebabkan oleh faktor-faktor di lingkungan kerja. Namun, stres kerja adalah semacam proses dinamis. Ketika ada kesenjangan antara permintaan kerja, seperti yang dievaluasi dan diidentifikasi oleh individu dan sumber daya, akan ada tekanan kerja. Oleh karena itu, stres kerja termasuk ketidakseimbangan fisik dan psikologis di lingkungan kerja (Margolis et al., 1974; Caplan dan Jones, 1975; Lin dan Chang, 2013), serta kesenjangan antara kompetensi individu, keterampilan, dan pekerjaan (Lin dan Chang, 2013).Seperti yang disebutkan di atas, stres kerja yang terlalu banyak memengaruhi kesehatan fisik pekerja, kesehatan psikologis, dan kinerja kerja.

Adversity Quotient menunjukkan sikap dan kemampuan untuk menghadapi sumber stres. Oleh karena itu, ada hubungan antara stres kerja dan adversity quotient, ketika kemampuan kontrol dari Adversity Quotient lebih tinggi, persepsi stres kerja harus lebih rendah. Ketika skor dimensi lebih tinggi, kehidupan individu tidak akan dipengaruhi oleh frustrasi, mereka akan dengan mudah memperlakukan rintangan, dan tidak akan memiliki hubungan negatif dengan kesulitan. Selain mengeksplorasi hubungan antara Adversity Quotient dan stres kerja. Penelitian sebelumnya (Shen et al., 2011; Shen dan Chang, 2009) 
menunjukkan hubungan antara stres kerja dan adversity quotient, dan juga seperti yang diskemukakan oleh Chand (2015), "stres kerja yang tepat dapat meningkatkan perhatian dan antusiasme untuk menangani pekerjaan yang sangat sulit".

Studi ini menunjukkan bahwa Adversity Quotient tidak hanya berhubungan dengan stres kerja, meskipun Adversity Quotient menurunkan stres pekerjaan, itu tidak sepenuhnya menjelaskan hubungan. Kunci untuk Adversity Quotient adalah mengubah kesulitan oleh CO2RE menjadi motivasi pribadi. Menurut literatur tentang Adversity Quotient dan stres kerja, ada hubungan antara keduanya, dan itu efektif. Adversity Quotient dapat menurunkan stres kerja Chand (2015), dan penelitian yang dilakukan oleh Stoltz (2015), AQ adalah ilmu ketahanan manusia, yaitu kapasitas orang untuk mengatasi stres dan kesulitan. AQ juga dapat disebut sebagai kemampuan orang untuk beradaptasi dengan baik terhadap stres, kesulitan, trauma atau tragedi.

$\mathrm{H}_{2}$ : Ada pengaruh negatif yang signifikan antara Adversity Quotient terhadap stres kerja.

Ghosh et al. (2013) mengatakan bahwa karyawan akan memiliki kecenderungan bertahan dan sukses menjalakan tugas pada perusahaan yang memiliki lingkungan kerja yang positif. Akila (2012) menyatakan bahwa lingkungan kerja non fisik sangat mempengaruhi stres karyawan, dengan adanya stres juga akan meningkatkan resistensi kariawan. Menurut Edwin (2012), lingkungan kerja telah menjadi salah satu faktor yang mempengaruhi stres kerja karyawan, karena jika karyawan memiliki pengalaman yang baik dengan lingkungan kerja, menyebabkan karyawan tersebut lebih bisa mengkondisikan 
kondisi pisikologis, dan lebih lama bertahan di dalam perusahaan. Menurut Chand (2015), lingkungan mempunyai pengaruh yang tinggi terhadap perilaku seseorang. Sebagai gambaran yang menunjukkan bahwa lingkungan yang baik akan membawa dampak yang baik terhadap individu. Kondisi lingkungan yang baik akan membawa dampak yang baik terhadap individu, demikian juga bila kondisi lingkungan buruk maka akan buruk pula dampaknya terhadap individu. Maka individu yang berkerja di tempat yang lingkungannya keras akan berpengaruh kuat terhadap kesehatan fisik dan mental individu.

Selain itu juga, menurut Shane (2005) menyatakan bahwa lingkungan kerja non fisik memiliki pengaruh terhadap kinerja dan beban yang di alami oleh seorang karyawan, lingkungan kerja non fisik yang buruk akan berdampak langsung terhadap kondisi pisikologis dari karyawan sehingga karyawan mudah mengalami stres kerja. Penelitian yang dilakukan oleh Susilo (2017) berlokasi di PT. Indo Bali menemukan hasil bahwa lingkungan kerja fisik dan lingkungan kerja non fisik secara simultan berpengaruh negatif dan signifikan terhadap stress kerja karyawan. Besarnya kontribusi pengaruh lingkungan fisik dan non fisik terhadap stress kerja termasuk dalam kategori tinggi yaitu sebesar 65,7 \%, sedangkan sisanya 34,3\% dipengaruhi oleh faktor faktor lain, seperti hasil angket yaitu masalah pribadi maupun masalah keluarga. Lingkungan kerja fisik secara parsial berpengaruh negatif signifikan terhadap stress kerja pada karyawan non produksi PT.Indo Baliy aitul 3,84\% demikian juga lingkungan non fisik secara parsial berpengaruh negatif dan signifikan terhadap stress kerja dengan kontribusi sebesar $10,30 \%$. 
$\mathrm{H}_{3}$ : Ada pengaruh negatif yang signifikan antara Lingkungan Kerja Non Fisik terhadap stres kerja.

Berdasarkan tinjauan literatur, kerangka kerja yang diilustrasikan pada Gambar 2.1 dikonseptualisasikan. Gambar di bawah, menggambarkan kerangka penelitian. Hipotesis hubungan antara konstruksi penelitian dikembangkan setelahnya.

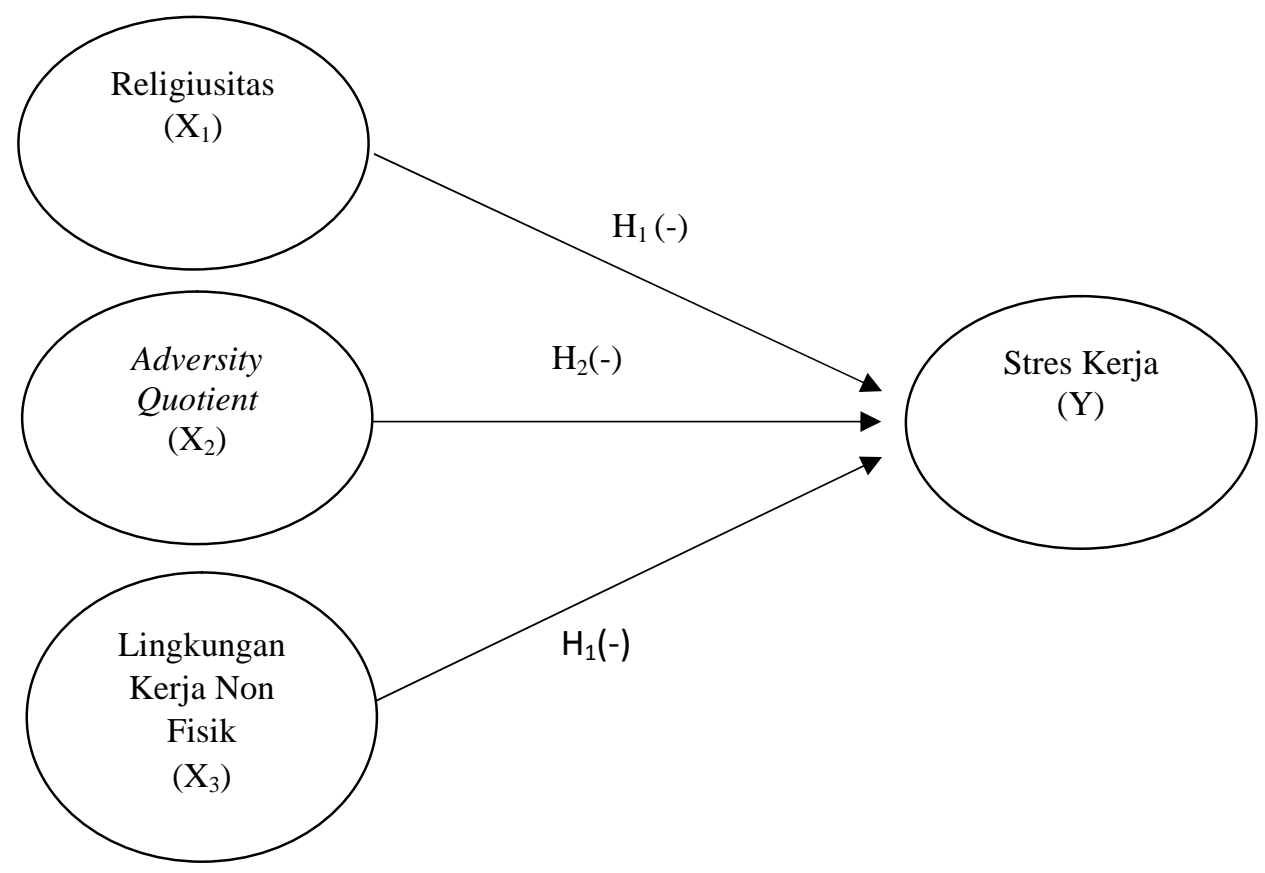

Gambar 1. Kerangka Konseptual

Sumber : Data diolah, 2018

\section{METODE PENELITIAN}

Lokasi dalam penelitian ini adalah Bank Perkreditan Rakyat Sri Partha Bali yang berada di Jl. Mohamad Yamin No. 7 Kota Denpasar Bali. Lokasi ini dipilih karena ditemukan masalah maslah mengenai stres kerja dari pegawai Bank 
Perkreditan Rakyat Sri Partha Bali, dimana diduga tinggi atau rendahnya stres kerja pegawai Bank Perkreditan Rakyat Sri Partha Bali di pengaruhi oleh religiusitas, adversity quotient dan lingkungan non fisik. Selain itu lokasi pemilihan didasarkan atas tersedianya data yang memadai dan mampu untuk diolah.

Penelitian ini karakteristik populasi adalah seluruh pegawai Bank Perkreditan Rakyat Sri Partha Bali penentuan sampel pada penelitian ini menggunakan sampel jenuh karena menggunakan keseluruhan dari anggota populasi. Teknik sampel yang akan digunakan pada penelitian ini adalah sampling jenuh. Sampling jenuh adalah penentuan teknik sampel dengan menggunakan semua anggota populasi. Pada tabel 1 akan ditunjukan jumlah karyawanBank Perkreditan Rakyat Sri Partha Bali.

Tabel 1.

Jumlah pegawai Bank Perkreditan Rakyat Sri Partha Bali

\begin{tabular}{llc}
\hline No. & Jabatan & Jumlah Karyawan (orang) \\
\hline 1. & Direktur Utama & 2 \\
2. & Direktur operasional & 1 \\
3. & Kepala bagian personalia dan Umum & 2 \\
4. & Kepala bagian marketing & 1 \\
5. & Kepala bagian operasional & 1 \\
6. & Kepala bagian kredit & 1 \\
7. & Accounting Officer & 3 \\
8. & Kasie accounting & 2 \\
9. & Kasie Teller & 3 \\
10. & Costumer Service dan pengaduan nasabah & 7 \\
11. & Teller & 5 \\
12. & Operasinal dan load prosessing & 5 \\
13. & Analisis Kredit & 5 \\
14. & Administrasi kredit & 3 \\
15. & Penilai Janiman dan surveyor & 6 \\
16. & Penanganan kredit bermasalah dan kolektor & 8 \\
Total & & $\mathbf{5 5}$ \\
\hline
\end{tabular}

Sumber: Bank Sri Partha Bali, 2018 
Penelitian ini menggunakan metode analisis regresi linear berganda untuk menjelaskan pengaruh variabel bebas (independen) dengan variabel terikat (dependen). Variabel bebas (independen) merupakan variabel yang mempengaruhi dalam penelitian ini yaitu variabel religiusitas $\left(\mathrm{X}_{1}\right)$, adversity qoutient $\left(\mathrm{X}_{2}\right)$ dan lingkungan kerja non fisik $\left(\mathrm{X}_{3}\right)$ sedangkan variabel terikat (dependen) merupakan variabel yang dipengaruhi dalam penelitian ini adalah Stres kerja (Y). Adapun model regresi linear Sederhana yang dapat dijabarkan dengan menggunakan persamaan sebagai berikut:

$$
\mathrm{Y}=\alpha+\beta_{1} \mathrm{X}_{1}+\beta_{2} \mathrm{X}_{2}+\beta_{3} \mathrm{X}_{3} \varepsilon
$$

Keterangan:

$$
\begin{array}{ll}
\alpha & =\text { Konstanta } \\
\beta_{1} & =\text { Koefisien regresi } \\
\mathrm{Y} & =\text { Stres Kerja } \\
\mathrm{X}_{1} & =\text { Religiusitas } \\
\mathrm{X}_{2} & =\text { Adversity Qoutient } \\
\mathrm{X}_{3} & =\text { Lingkungan Kerja Non Fisik } \\
\varepsilon & =\text { Error }
\end{array}
$$

\section{HASIL DAN PEMBAHASAN}

Penelitian ini melibatkan 55 responden yang sesuai dengan kriteria sampel. Adapun identitas responden yang ikut ambil bagian dari penelitian ini meliputi jenis kelamin, usia, tingkat pendidikan, dan pekerjaan yang akan diuraikan sebagai berikut.

Tabel 2.

Data Jenis Kelamin Responden

\begin{tabular}{llll}
\hline No. & Jenis Kelamin & Jumlah & Persentase \\
\hline 1. & Laki-laki & 25 & 45,45 \\
2. & Perempuan & 30 & 54,55 \\
& Jumlah & 55 & 100 \\
\hline
\end{tabular}

Sumber: Data diolah, 2018

Berdasarkan hasil penelitian pada Tabel 2 menunjukkan sebagian besar responden berjenis kelamin perempuan sebanyak 30 orang atau $54,55 \%$. Kondisi 
ini menunjukkan bahwa secara umum responden pada penelitian ini merupakan perempuan.

Karakteristik responden penelitian ini jika dilihat dari usia, maka gambaran distribusinya dapat dilihat seperti Tabel 3 berikut ini:

Tabel 3.

Data Usia Responden

\begin{tabular}{llll}
\hline No. & Usia (th) & Frekuensi & Persentase \\
\hline 1. & $18-23$ & 6 & 10,90 \\
2. & $24-29$ & 42 & 76,40 \\
3. & $\geq 42$ & 7 & 12,70 \\
& Jumlah & 55 & 100 \\
\hline
\end{tabular}

Sumber: Data diolah, 2018

Berdasarkan hasil penelitian pada Tabel 3 menunjukkan sebagian besar responden berusia 24-29 tahun sebanyak 42 orang atau 76,40\%. Sedangkan responden dengan range usia 18-23 tahun sebanyak 6 orang atau 10,90\% dan 3641 tahun sebanyak 7 orang atau $12,70 \%$. Kondisi ini menunjukkan bahwa secara umum responden pada penelitian ini merupakan anak muda usia 24-29 tahun yang bekerja di Bank Sri Partha Bali.

Karakteristik responden penelitian ini jika dilihat dari tingkat pendidikan, maka gambaran distribusinya dapat dilihat seperti Tabel 4 berikut ini:

Tabel 4.

Data Tingkat Pendidikan Responden

\begin{tabular}{llll}
\hline No. & Tingkat Pendidikan & Frekuensi & Persentase \\
\hline 1. & SMA/sederajat & 0 & 0 \\
2. & Diploma & 6 & 10,90 \\
3. & Sarjana & 49 & 89,10 \\
& Jumlah & 55 & 100 \\
\hline
\end{tabular}

Sumber: Data diolah, 2018

Berdasarkan hasil penelitian pada Tabel 4 menunjukkan sebagian besar responden dengan tingkat pendidikan terakhir Sarjana sebanyak 49 orang atau $89,10 \%$. Sedangkan responden yang berpendidikan terakhir pascasarjana 
sebanyak 6 orang atau 10,90\% sedangkan tingkat pendidikan SMA/sederajat tidak

\begin{tabular}{llccccc}
\hline No. & \multicolumn{1}{c}{ Model } & \multicolumn{2}{c}{$\begin{array}{c}\text { Unstandardized } \\
\text { Coefficients } \\
\text { Std. Error }\end{array}$} & $\begin{array}{c}\text { Standardized } \\
\text { Coefficients } \\
\text { Beta }\end{array}$ & T & Sig. \\
\hline 1 & Constant & 45,526 & 2,151 & & 21,161 & 0,000 \\
& Religiusitas & $-0,457$ & 0,164 & $-0,344$ & $-2,780$ & 0,008 \\
& Adversity Qoutient & $-0,412$ & 0,164 & $-0,245$ & $-2,517$ & 0,015 \\
& Lingkungan Kerja Non & $-0,454$ & 0,141 & $-0,372$ & $-3,231$ & 0,002 \\
& Fisik & & & & & \\
\hline
\end{tabular}

ada. Kondisi ini menunjukkan bahwa secara umum responden pada penelitian ini memiliki tingkat pendidikan terakhir yang ditempuh yaitu sarjana.

Analisis regresi linier berganda untuk mencari koefisien regresi yang akan menentukan apakah hipotesis yang dibuat akan diterima atau di tolak. Adapun hasil analisis linier berganda dapat dilihat pada tabel berikut:

\section{Tabel 5.}

\section{Hasil Uji Regresi Linear Berganda}

Sumber: Data diolah, 2018

Berdasarkan Tabel 5 maka persamaan regresi linear berganda yang dapat dibentuk adalah sebagai berikut.

$$
Y=45,526+-0,457 X_{1}+-0,412 X_{2}+-0,454 X_{3}
$$

Makna dari koefisien regresi tersebut dijelaskan bahwa Nilai koefisien regresi Religiusitas $\left(\mathrm{X}_{1}\right)$ sebesar $-0,457$ memiliki arti Religiusitas berpengaruh negatif terhadap Stres Kerja karyawan pada Bank Sri Partha Bali, bila nilai Religiusitas $\left(\mathrm{X}_{1}\right)$ naik maka nilai dari Stres Kerja (Y) akan mengalami Penurunan.

Nilai koefisien regresi Adversity Qoutient $\left(\mathrm{X}_{2}\right)$ sebesar -0,412 memiliki arti Adversity Qoutient berpengaruh negatif terhadap Stres Kerja karyawan pada Bank 
Sri Partha Bali, bila nilai Adversity Qoutient $\left(\mathrm{X}_{2}\right)$ naik maka nilai dari Stres Kerja (Y) akan mengalami Penurunan.

Nilai koefisien regresi Lingkungan Kerja Non Fisik $\left(\mathrm{X}_{3}\right)$ sebesar -0,454 memiliki arti Lingkungan Kerja Non Fisik berpengaruh negatif terhadap Stres Kerja karyawan pada Bank Sri Partha Bali, bila nilai Lingkungan Kerja Non Fisik $\left(\mathrm{X}_{3}\right)$ naik maka nilai dari Stres Kerja $(\mathrm{Y})$ akan mengalami Penurunan.

Hasil uji $\mathrm{F}$ dapat dijelaskan dengan nilai signifikansi anova $<\alpha=0,05$ maka model ini dikatakan layak atau variabel bebas mampu menjelaskan variabel terikat, hasil uji F dapat dilihat dalam Tabel 6 berikut.

Tabel 6.

\section{Hasil Uji F}

\begin{tabular}{lccclc}
\hline \multicolumn{1}{c}{ Model } & Sum of Squares & Df & Mean Square & F & Sig. \\
\hline Regression & 3,952 & 3 & 1,317 & 1,170 & 0,000 \\
Residual & 57,405 & 51 & 1,126 & & \\
Total & 61,357 & 54 & & & \\
\hline Sumber: Data diolah, 2018 & & & & &
\end{tabular}

Sumber:Data diolah, 2018

Berdasarkan Tabel 6 menunjukkan nilai signifikansi sebesar 0,000 yang lebih kecil dari nilai $\alpha=0,05$ maka model regresi linear berganda layak digunakan sebagai alat analisis untuk menguji pengaruh variabel bebas terhadap variabel terikat.

Berdasarkan Tabel 5nilai signifikansi uji t sebesar 0,008 lebih kecil daripada $\alpha=0,05$, maka $\mathrm{H}_{0}$ ditolak. Hasil ini mendukung hipotesis $\mathrm{H}_{1}$ yang menyatakan bahwa religiusitas berpengaruh negatif terhadap stres kerja pada Bank Perkreditan Rakyat Sri Partha Bali. Hasil penelitian ini mendukung hipotesis pertama yaitu religiusitas berpengaruh negatif terhadap stres kerja pada Bank Perkreditan Rakyat Sri Partha Bali. Hasil penelitian ini sesuai dengan penelitian yang 
dilakukan oleh Eugene J. Kutcher dari Rider University dan Jennifer Bragger dari Montclair State University, dengan judul "The Role of Religiosity in Stress, Job Attitudes, and Organizational Citizenship Behavior" yang di muat dalam Article inJournal of Business Ethics August 2010. Satu penjelasan yang jelas adalah bahwa religiusitas memiliki dampak langsung pada tingkat stres yang dialami karyawan dan tingkat kelelahan yang dialami karyawan. Artinya, ketangguhan yang diberikan oleh keyakinan dan ketaatan beragama benar-benar mengurangi tingkat stres terkait pekerjaan yang dialami karyawan.

Berdasarkan Tabel 5 nilai signifikansi uji t sebesar 0,015 lebih kecil daripada $\alpha=0,05$, maka $\mathrm{H}_{0}$ ditolak. Hasil ini mendukung hipotesis $\mathrm{H}_{2}$ yang menyatakan bahwa adversity qoutient berpengaruh negatif terhadap stres kerja pada Bank Perkreditan Rakyat Sri Partha Bali. Hasil penelitian ini mendukung hipotesis kedua yaitu adversity qoutient berpengaruh negatif terhadap stres kerja pada Bank Perkreditan Rakyat Sri Partha Bali. Hasil penelitian sam dengan penelitian yang dikemukakan oleh Shen et al.(2011), Adversity Quotient menunjukkan sikap dan kemampuan untuk menghadapi sumber stres. Oleh karena itu, ada hubungan antara stres kerja dan adversity quotient, ketika kemampuan kontrol dari Adversity Quotient lebih tinggi, persepsi stres kerja harus lebih rendah. Sama halnya ketika seorang karyawan memiliki tingkat adversity qouetient yang tinggi maka stres kerja seorang karyawan akan menjadi turun (Shen et al., 2011)

Berdasarkan Tabel 5 nilai signifikansi uji t sebesar 0,002 lebih kecil daripada $\alpha=0,05$, maka $\mathrm{H}_{0}$ ditolak. Hasil ini mendukung hipotesis $\mathrm{H}_{3}$ yang 
menyatakan bahwa Lingkungan kerja non fisik berpengaruh negatif terhadap stres kerja pada Bank Perkreditan Rakyat Sri Partha Bali. Hasil penelitian ini mendukung hipotesis ketiga yaitu lingkungan kerja non fisik berpengaruh negatif terhadap stres kerja pada Bank Perkreditan Rakyat Sri Partha Bali. Penelitian yang dilakukan oleh Shane (2005) menyatakan bahwa lingkungan kerja non fisik memiliki pengaruh terhadap kinerja dan beban yang di alami oleh seorang karyawan, lingkungan kerja non fisik yang buruk akan berdampak langsung terhadap kondisi pisikologis dari karyawan sehingga karyawan mudah mengalami stres kerja.

Berdasarkan penelitian yang telah dilakukan, terdapat beberapa hal yang menjadi keterbatasan di dalam penelitian ini. Adapun keterbatasan yang dapat diuraikan, yaitu:Penelitian ini hanya mencari adanya pengaruh religiusitas, adversity qoutient dan lingkungan kerja non fisik terhadap stres kerja, namun masih banyak variabel lain yang mungkin dapat dipergunakan.Adanya kekhawatiran terhadap responden, dengan indikasi responden tidak memahami maksud dari pernyataan kuesioner sehingga tidak mengerti dan menjawab dengan baik.Masih adanya keterbatasan tenaga, biaya, dan waktu dalam penelitian ini.

\section{SIMPULAN DAN SARAN}

Berdasarkan pembahasan yang telah diuraikan pada bab sebelumnya, maka diperoleh simpulan bahwa religiusitas memiliki pengaruh negatif dan signifikan terhadap stres kerja. Hal ini menunjukkan semakin tinggi tingkat religiusitas yang dimiliki oleh karyawan di tempat kerja maka semakin rendah stres kerja dirasakan oleh karyawan dalam organisasinya. 
Adversity qoutent memiliki pengaruh negatif dan signifikan terhadap stres kerja. Hal ini menunjukkan semakin tinggi tingkat adversity qoutent yang dimiliki oleh karyawan di tempat kerja maka semakin rendah stres kerja dirasakan oleh karyawan dalam organisasinya.

Lingkungan kerja non fisik memiliki pengaruh negatif dan signifikan terhadap stres kerja. Hal ini menunjukkan semakin baik lingkungan kerja non fisik di tempat kerja maka semakin rendah stres kerja dirasakan oleh karyawan dalam organisasinya.

Saran yang dapat diberikan berdasarkan hasil penelitian dan pembahasan adalah pimpinan Bank Perkreditan Sri Partha Bali sebaiknya selalu mencari informasi tentang tingkat adversity qoutent dari karyawan, sehingga karyawan yang memiliki adversity qoutent yang tinggi, sehingga pimpinan mampu mengetahui tingkat adversity dari masing masing karyawan. Pimpinan Bank Perkreditan Sri Partha Bali sebaiknya juga memperhatikan religiusitas dan adversity qoutent yang dimiliki oleh setiap karyawan agar mereka dapat bekerja dengan baik dan juga memperhatikan kondisi lingkungan kerja non fisik agar tercipta kenyamanan karyawan agar karyawan terhindar dari stres kerja. Pada penelitian selanjutnya diharapkan dapat mengembangkan variabel-variabel dalam penelitian ini, karena masih terdapat variabel lain yang belum disertakan dalam penelitian ini.

\section{REFERENSI}

Allport, G. W. and J. M. Ross: (2015), 'Personal Religious Orientation and Prejudice', Journal of Personality and Social Psychology 5(2), pp 432-443. 
Ancok, Djamaludin dan Fuad Nashori Suroso. (2009). Psikologi Islam Solusi Islam Atas Problem-Problem Psikologi. Yogyakarta: Pustaka Pelajar. Jurnal Studia Pisikologi, 1 (3), hal. 47-62.

Adriaenssens, L., De Prins, P., \& Vloeberghs, D. (2016). Work experience, work stress and HRM at the university. Management Bagozzi, R. P. \& Yi, Y. (1988). On the evaluation of structural equation models. Journal of the academy of marketing science, 16(1)

Akila. (2012). A study on employee retention among executives at BGR energy systems I.TD, Chennai. International Journal of Marketing, Financial Services \& Management Research, 1 (9), pp. 18-32.

Bartifai, T. and Schultzberg, M. (1993). Cytokines in neuronal cell types, Neurochem, Int, Vol.22, pp.435-444.

Caughey, J. (2016). Psychological distress in staff of a social services district office: A pilot study. British Journal of Social Work, 13 (26), pp. 389398.

Conlin, M.: (2009), November 1, 'Religion in the Workplace: The Growing Presence of Spirituality in Corporate America', Journal of Rural Community Psycology.18 (32) Pp. 150-158.

Carone, D.A., and Barone, D.F. (2001). A social cognitive perspective on religious beliefs: Their functions and impact on coping and psychotherapy. Journal of Clinical Psychology Review, 21(32), Pp. 989-1003.

Cornwall, M., Albrecht, S. L., Cunningham, P. H., Pitcher, B. L. (2014). The dimensions of religiosity: A conceptual model with an empirical test. Review of Religious Research, (2). pp. 226-244.

Caplan, R. D. \& Jones, K. W. (2013). Effects of Work Load, Role Ambiguity, and Type A Personality on Anxiety, Depression, and Heart Rate. Journal of Applied Psychology, vol. 60: 713-719.

Chand, K. (2015). Pressures, Stresses, Anxieties, and On-Job Safety of the School Superintendent. (ERIC Document Reproduction Service No. ED 249706)

Edwin. (2012). Analisis Pengaruh Lingkungan Kerja Dan Kompensasi Terhadap Kepuasan Kerja Serta Dampaknya Terhadap Retensi Karyawan Pada PT Lion Wings. pp: 1-31.

Eugene J. Kutcher and Jennifer Bragger (2010). "The Role of Religiosity in Stress, Job Attitudes, and Organizational Citizenship Behavior"Article in Journal of Business Ethics August 2010. 12 (8), pp. 102-109

Gibson, D.: (2005), September, Spirituality in America: God on the Job? Ladies Home Journal. Journal of Applied Psychology 5(23), pp. 286-293. 
Ghosh, P., Satyawadi, R., Prasad Joshi, J. dan Shadman, M. (2013). Who stays with you? Factors predicting employees' intention to stay. International Journal of Organizational Analysis, 21 (3), pp. 288-312.

Koenig, H. G., M. E. McCullough and D. B. Larson. (2014), Journal of Handbook o of Religion and Health Oxford Uni- versity Press, New York, NY 4 (23), pp. 213-222.

Kosmin, B. A., E. Mayer and A. Keysar: (2001), Journal of American Religious Identification Survey. Graduate Center of the City University of New York, New York. 1 (12), pp. 78-86.

Kresna Astri. (2009)Hubungan Antara Stres Dan Religiusitas Pada Dewasa Muda Beragama Islam.Skripsi. Fakultas Psikologi Universitas Indonesia,Depok 7 (39), Hlm. 56-62.

Kasberger, E.R. (2015). A correlation study of post-divorce adjustment and reliious coping strategies in young adult of divorced families. Second Annual. Undergraduate Research Symposium Charis Journal of Institute of Wisconsin Lutheran College. Milwaukee, 3 (30), pp. 276-292

Hallberg, U. E. and M. Sverke: (2014). 'Construct Validity of the Maslach Burnout Inventory: Two Swedish Health Care Samples', European Journal of Psychological Assessment 4 (20), Pp. 320-338.

Harrell, S. P. (2016). 'A Multidimensional Conceptuali- zation of Racism-Related Stress: Implications for the Well-Being of People of Color', American Journal of Orthopsychiatry 12 (70), pp. 42-57.

Leiter, M. P. and C. Maslach. (2016). 'The Impact of Interpersonal Environment on Burnout and Organi- zational Commitment', Journal of Organizational Behavior 9 (47), pp. 297-308.

Levin, J. S., L. M. Chatters, C. G. Ellison and R. J. Taylor: (2012). 'Religious Involvement, Journal of Occupation and Organizational Psychology, 8 (5), pp: 407-416.

Laksmono, Hari.K. (2017) Tinjauan Singkat Adversity Quotient. Anima, Indonesian Psychological Journal. Vol.17, No 1, 63-68.

Leman. (2007). Memahami Adversity Quotient. Anima (Indonesian Psychological Journal).

Lin,Y. L. \& Chang, W. J. (2010). The mediating effect of the organizational socialization on mentoring: job stress relationship. Journal of Human Resource Management, 10(3): pp. 75-96

Maslach, C., Jackson, S. \& Leiter, M. (2016). Maslach Burnout Inventory Manual. Palo Alto: Journal of Consulting Psychologists Press. 6 (78). Pp.135-142 
Mangkunegara, AP. (2017). Manejemen Sumber Daya Manusia Perusahaan. Bandung: PT. Remaja Rosdakarya

Mira Isminari. (2011).“Pengaruh Regiulitas dan Advesity Quotient Terhadap Stres Kerja Pada Agen Asuransi Jiwa Bersama Bumi Putra 1912” . Jurnal Manajemen Fakultas Ekonomi Universitas Indonesia, 4 (22), hal. 1-20.

Marc R. Nuwer, (2015). Quantitative EEG: I. Techniques and Problem of Frequency Analysis and Topographic Mapping, Journal of Clinical Neurophysiology, Vol.5 No.1, pp.1-43.

Nitisemito, Alex S. (2000). Manajemen Personalia. Jakarta : Ghalia Indonesia.

Nashori. (2007). Pelatihan Adversity Intellegence untuk Meningkatkan Kebermaknaan Hidup Remaja Panti Asuhan. Jurnal Psikologi No.23 ThnXII Januari 2007

Park, C., L. H. Cohen and L. Herb. (2013). 'Intrinsic Religiousness and Religious Coping as Life Stress Moderators for Catholics versus Protestants', Journal of Personality and Social Psychology (2) 59, pp. 562-574.

Pollard, L. J. and L. W. Bates: (2014) 'Religion and Per- ceived Stress Among Undergraduates During Fall 2001 Final Examinations', Journal of Psychological Reports 11 (95), pp. 999-1007.

Phoolka, S., Kaur, N. (2012). Adversity Quotient: A new Paradigm to Explore, International Journal of Contemporary Business Studies, 2, 4

Rammohan and Subbakrishna, D.K. (2013). Religoius coping and psychological well-being in carers of relatives with schizophrenia. Acta Psy- chiatrica Scandinavica, 105(5), pp. 356-362.

Robbins, S.P. (2007). Perilaku Organisasi. Jakarta: PT. Macanan Jaya Cemerlang

Ross, C. E.: (2015) 'Religion and Psychological Distress', Journal for the Scientific Study of Religion 9 (56), 236-245.

Rotter, J.(2015). Generalized expectancies for internal versus external locus of control of reinforcement, Psychological Monographs, 81(1, Whole No. 609).

Sedarmayanti. (2011).Tata Kerja dan Produktivitas Kerja : Suatu Tinjauan Dari Aspek Ergonomi Atau Kaitan Antara Manusia Dengan Lingkungan Kerjanya. Cetakan Ketiga. Bandung: Mandar Maju.

Siagian, S.P. (2016)Manajemen sumber daya manusia. (13th Ed.). Jakarta: Bumi Aksara

Sudarsono. (2008)Kenakalan Remaja. Jakarta : PT RINEKA CIPTA. 